\title{
AS METODOLOGIAS ATIVAS E AS APROXIMAÇÕES ENTRE O ENSINO E A APRENDIZAGEM NA PRÁTICA PEDAGÓGICA UNIVERSITÁRIA
}

\author{
Maiza Taques Margraf Althaus ${ }^{1}$ \\ Viviane Aparecida Bagio ${ }^{1}$
}

\section{RESUMO}

No contexto do desenvolvimento da prática pedagógica universitária, uma das preocupações dos professores refere-se ao encaminhamento metodológico dos processos de ensino e aprendizagem. Neste trabalho, propõe-se discutir sobre as possibilidades e os limites da prática pedagógica quando pautada na perspectiva da transmissão do conhecimento, por meio de aulas expositivas, em contraposição às propostas de ensino pela via das metodologias ativas. A metodologia adotada para o desenvolvimento do presente estudo é bibliográfica, orientada na leitura e análise de obras referentes ao tema proposto. Buscando apoio nas pesquisas de Nóvoa e Amante (2015), Mainardes (2008), Heacox (2006), Pozo (2002) e Roldão (2007), entre outros, o texto problematiza a dimensão didática da docência universitária, a fim de ressignificar e aproximar o ensinar do aprender. $O$ estudo desenvolvido também evidenciou algumas possibilidades de encaminhamento metodológico na aula universitária, em situações didáticas planejadas em que se privilegia a perspectiva ativa dos estudantes em suas aprendizagens.

Palavras-chave: Metodologias ativas. Docência universitária. Ensino.

\footnotetext{
${ }^{1}$ Departamento de Pedagogia, Universidade Estadual de Ponta Grossa, Ponta Grossa, PR, Brasil.
} 
THE ACTIVE METHODOLOGIES AND THE APPROXIMATIONS BETWEEN TEACHING AND LEARNING IN UNIVERSITY PEDAGOGICAL PRACTICE

\author{
Maiza Taques Margraf Althaus \\ Viviane Aparecida Bagio
}

\begin{abstract}
In the context of the development of university pedagogical practice, one of the concerns of teachers refers to the methodological referral of teaching and learning processes. This paper proposes to discuss the possibilities and limits of pedagogical practice when guided by the perspective of the transmission of knowledge, through lectures, as opposed to teaching proposals through active methodologies. The methodology adopted for the development of the present study is bibliographical, based on the reading and analysis of works related to the proposed theme. In the search for support in the researches of Nóvoa and Amante (2015), Mainardes (2008), Heacox (2006), Pozo (2002) and Roldão (2007) among others, the text problematizes the didactic dimension of university teaching in order to re-significate and approach teaching to learning. The study developed also showed some possibilities of methodological referral in the university classroom, in planned didactic situations in which the students' active perspective on their learning is privileged.
\end{abstract}

Keywords: Active methodologies. University teaching. Teaching. 


\title{
INTRODUÇÃO
}

\begin{abstract}
Como nos bons filmes, uma boa instrução é aquela em que não só há boas réplicas, um diálogo eficaz, mas uma mudança sutil e progressiva nos personagens, que vão se enchendo de nuances à medida que se desenvolve a trama, de forma que no final o durão do começo nos sai um romântico incorrigível, o bondoso fazendeiro um personagem inquietante com um passado turvo, e o espião na realidade é um espião duplo, que acaba sendo dos bons, ou seja, dos nossos. Também a aprendizagem e a instrução requerem uma transição, uma mudança de papéis, não menos importante por ser menos emocionante. A entrega progressiva da responsabilidade da aprendizagem para os aprendizes simboliza, de alguma forma, a transição para essa nova cultura da aprendizagem (POZO, 2002, p. 264).
\end{abstract}

No filme Vem dançar, o dançarino profissional Pierre Dulaine (interpretado por Antonio Banderas) torna-se voluntário para dar aulas de dança em uma escola pública de Nova York. Diante da resistência de seus alunos no que respeita aos métodos clássicos, Pierre propõe um novo estilo de dança, a fim de envolver os alunos na proposta de ensino e aprendizagem.

Uma das cenas do filme, em que os atores interpretam o tango, motivou-nos a introduzir e problematizar o tema que aqui nos propomos a desenvolver: "[...] o tango é uma coisa para dois. Se os mestres se movem para um lado e os aprendizes para outro será difícil que a aprendizagem seja eficaz" (POZO, 2002, p. 264). De fato, pontua o autor, ensinar e aprender são dois verbos que nem sempre são conjugados concomitantemente. A prática pedagógica universitária aproxima-se, desse modo, das coreografias no mundo da dança: nós, os docentes, organizamos as metodologias de ensino (coreografias) que, ao serem colocadas em cena, orientam os processos de aprendizagem dos estudantes (ZABALZA, 2006).

O questionamento inicial que neste artigo se discute é o seguinte: como se configuram, no desenvolvimento da prática pedagógica universitária, as aproximações entre os processos de ensino e aprendizagem na perspectiva das metodologias ativas? Qual seria a especificidade da ação didática do professor universitário ao planejar o trabalho pedagógico nessa perspectiva? Ou ainda, quais papéis protagonizam os estudantes universitários e seus professores quando a aula é planejada e desenvolvida pela via das metodologias ativas?

O texto foi organizado em quatro momentos constitutivos: primeiramente, uma contextualização sobre a prática pedagógica na docência universitária. Num segundo momento, 
problematizamos a metodologia de ensino na perspectiva da transmissão do conhecimento, a partir do seguinte questionamento: é um processo ativo de quem? Em seguida, trazemos alguns autores para referenciar o tema central do trabalho: a prática pedagógica universitária por meio das metodologias ativas. Nesse item, apresentamos também algumas orientações metodológicas para os professores atuantes no ensino superior. Por fim, na última seção, apresentamos algumas possibilidades dos momentos da aula universitária com metodologias ativas.

\section{SOBRE O ENSINO E SEUS ELEMENTOS}

A temática privilegiada neste trabalho articula-se, numa dimensão mais ampla, ao contexto da formação pedagógica para e na docência do ensino superior. Não raras vezes, as universidades têm promovido congressos sobre a temática das metodologias ativas, a fim de possibilitar o envolvimento dos professores na organização e gestão da prática pedagógica universitária. Porém, em que pese o fato da relevância das iniciativas voltadas para o desenvolvimento dos saberes pedagógicos, há que se considerar que os professores universitários carecem de formação pedagógica no que respeita aos fundamentos da docência: filosofia da educação, psicologia da educação, teorias do conhecimento, políticas e gestão educacional, e, indiscutivelmente, numa dimensão mais específica sobre o ensino, o suporte do campo da formação didática para a docência universitária.

O estudo de Cunha e Soares ratifica esse pensamento:

[...] a docência do ensino superior é uma atividade complexa do ponto de vista político, social, intelectual, psicológico e pedagógico, cujos saberes e competências imprescindíveis ao seu exercício, sumariamente apresentados neste estudo, a configuram como um campo específico de intervenção profissional. Dessa forma, como acontece com as demais profissões, não podem ser adquiridos por imitação, e, sim, mediante uma formação específica e consistente (CUNHA; SOARES, 2010, p. 30).

Por ser complexa, múltiplos saberes constituem a prática pedagógica universitária. Não somente os saberes do campo disciplinar, mas, sobremaneira, os saberes pedagógicos que, articulados com os saberes da experiência profissional, aproximam-se dessa construção da docência. 
Os estudos desenvolvidos por Franco (2012, p. 156) apontam que uma prática pedagógica é constituída por um conjunto complexo e multifatorial. Ou seja, há ingredientes estruturantes das práticas pedagógicas, tais como as decisões dos professores, os princípios, as ideologias e também as estratégias didáticas que o professor pretende desenvolver no contexto da aula. Dito de outra maneira, a prática pedagógica de um professor interpenetra na cultura da instituição em que ele atua como docente, ao mesmo tempo que expressa o contexto cultural do professor. Desse modo, pensar em alguma opção metodológica extrapola o viés das escolhas didáticas, pois as decisões do "como ensinar" sempre estão articuladas com as decisões do "por que" e do "para que" ensinar (VEIGA, 1994).

Neste contexto, o professor universitário, ao fazer uma opção metodológica, precisa ter presente que há distintas concepções de conhecimento que estão articuladas e presentes no desenvolvimento da prática pedagógica no ensino de graduação.

Segundo Roldão (2003, p. 44), o conceito de ensinar está relacionado a uma intencionalidade de uma ação específica "[...] no sentido de produzir, promover, possibilitar a aprendizagem de alguma coisa a alguém".

Gauthier (1998, p. 371) diz que o ensino é um trabalho interativo, pois apresenta a "[...] particularidade de agir diretamente sobre o elemento humano; seu produto [a aprendizagem] assumirá a forma de uma mudança no usuário [discente]". Além disso, o ensino pressupõe a perpetuação do conhecimento aos estudantes, no entanto, ele não deve ocorrer de modo exclusivamente transmissivo, pois o significado de ensinar decorre "[...] através dos elementos envolvidos em tal prática: o aluno, o conhecimento, o professor e as situações didáticas" (NADAL; PAPI, 2007, p. 22).

Mas qual seria o papel do ensino como transmissão/exposição dos conteúdos na aula universitária? Quais as possibilidades ou limites dessa transmissão mesmo quando o professor opta pela via das metodologias ativas? Ou ainda, como pensar nos diferentes momentos da aula com o propósito de ensinar por meio das metodologias ativas? 


\title{
METODOLOGIA DE ENSINO NA PERSPECTIVA DA TRANSMISSÃO DO CONHECIMENTO NA PRÁTICA PEDAGÓGICA UNIVERSITÁRIA: PROCESSO ATIVO DE QUEM?
}

\begin{abstract}
Metodologia refere-se ao método, ao caminho buscado para se chegar a determinado objetivo ou fim; o método nos dará uma explicação minuciosa, detalhada, rigorosa e exata das ações desenvolvidas no caminho buscado. Assim, refletir sobre metodologia ativa é trazer os elementos que a explicam, descrevem suas categorias ou elementos determinantes, tanto no fundamento quanto na prática docente (ANASTASIOU, 2014, p. 19).
\end{abstract}

A metodologia de ensino sob a perspectiva expositiva ou transmissiva é aquela em que o conhecimento é compreendido como processo de mera transmissão de um sujeito que sabe a outro que não sabe. Segundo Nóvoa e Amante (2015, p. 24),

[...] o conhecimento pertence ao professor, que se serve do quadro negro para o transmitir aos alunos. Esta realidade induz uma pedagogia transmissiva, fortemente marcada por uma relação "vertical" entre professor e alunos. O conceito anglo-americano de lecture (palestra, preleção, lição) traduz bem este modelo de ensino. E não podemos esquecer que lecture (em língua inglesa) vem diretamente de lecture (em língua francesa), isto é, ler para os outros. Está aqui a raiz das didáticas que ainda hoje dominam os ambientes universitários.

O ensino desenvolvido sob essa perspectiva é um processo ativo do professor. Os estudantes universitários não se preparam para as aulas, pois lhes compete apenas entrar na sala e ouvir a exposição do professor. A avaliação é o momento final do processo, sem estar articulada com os processos de ensino e aprendizagem (não é contínua). O professor acredita que, se o aluno não aprendeu, o problema é exclusivamente deste e que não é preciso rever o processo de ensino. Nessa modalidade, o professor transmite o conhecimento sem interação com os alunos, que ouvem (passivamente). O professor universitário planeja, estuda, prepara materiais, e ao chegar em sala explica, lê os slides, expõe, repassa e transmite o conteúdo da aula. Ou seja, aprende repetidas vezes, ao passo que o aluno limita-se a ouvir a explanação do professor.

A organização do espaço na aula expositiva tem como ponto central o quadro, "favorecendo dinâmicas de comunicação vertical entre o professor e os alunos. A homogeneização do espaço-tempo é um traço importante de uma pedagogia universitária que, ainda hoje, 
continua marcada pelos espaços físicos e pelo tempo dos horários e calendários" (NÓVOA; AMANTE, 2015, p. 24).

No método tradicional, "[...] o importante é o produto do ensino, desprezando-se o seu processo, o que explica o papel ativo do professor (falante), repassador de conteúdos e o papel passivo dos alunos que ouvem, anotam e devolvem nas provas" (ROSSO; TAGLIEBER, 1992, p. 43).

Tal entendimento também é discutido com propriedade por Roldão (2007, p. 95),

$$
\begin{aligned}
& \text { o entendimento de ensinar como sinónimo de transmitir um saber } \\
& \text { deixou de ser socialmente útil e profissionalmente distintivo da } \\
& \text { função em causa, num tempo de acesso alargado à informação e de } \\
& \text { estruturação das sociedades em torno do conhecimento enquanto } \\
& \text { capital global. }
\end{aligned}
$$

Segundo Imbernón (2012), o problema não está na aula expositiva, mas em como ela se apresenta na prática, como se realiza a transmissão do conhecimento, ou seja, como a aula expositiva se transforma em uma aula transmissora de comunicação unidirecional e entediante. De acordo com Moran (2015), para qualquer pessoa a aprendizagem é maior quando há prática e reflexão do que apenas a explicação, pois os conceitos mais simples, conteúdos básicos, ela consegue estudar de acordo com o seu ritmo, mas as atividades em grupo para o aprofundamento permitem "ir além" do estudo individual.

Para o autor, quando curtas e bem planejadas, as aulas expositivas podem ser úteis desde que ocorram de forma dialogada, ou seja, considerando os questionamentos, contribuições e a participação dos acadêmicos. Além disso, destaca que, atualmente, elas possuem mais sentido ao iniciar (motivação, cenários, perspectivas) ou concluir (retomada, síntese, resultados) um novo conhecimento e, ao longo do processo de ensino-aprendizagem, o professor deve orientar e mediar as atividades (individuais e coletivas), a fim de motivar os alunos a encontrar caminhos próprios de aquisição do conhecimento, por meio de um processo didático que mobilize a pesquisa e a avaliação, com uma formação humana e crítica, para além do ensino e aprendizagem.

Como síntese a esta perspectiva aqui discutida, apresentamos o Quadro 1, a seguir: 
Quadro 1 - Perspectivas das metodologias de ensino na transmissão do conhecimento na prática pedagógica universitária

\begin{tabular}{|c|c|c|}
\hline Sujeito & Professor & Aluno \\
\hline Participação & Ativa & Passiva \\
\hline Aulas & $\begin{array}{l}\text { Dependem exclusivamente da } \\
\text { sua atuação }\end{array}$ & $\begin{array}{l}\text { O aluno não se prepara para as aulas, apenas } \\
\text { ouve a exposição do o professor }\end{array}$ \\
\hline Conhecimento & $\begin{array}{l}\text { Apresentado na perspectiva da } \\
\text { transmissão por meio de aulas } \\
\text { expositivas }\end{array}$ & $\begin{array}{l}\text { Perspectiva da assimilação e retenção do que } \\
\text { é trazido via exposição oral do professor }\end{array}$ \\
\hline $\begin{array}{l}\text { Processo de Ensino } \\
\text { e Aprendizagem }\end{array}$ & $\begin{array}{l}\text { O professor, ao ensinar, } \\
\text { desconsidera que também } \\
\text { aprende }\end{array}$ & $\begin{array}{l}\text { Responsável pela aprendizagem, devendo } \\
\text { estudar antes das provas }\end{array}$ \\
\hline Avaliação & Somativa e ao final do processo & $\begin{array}{l}\text { O aluno é avaliado por meio de um único } \\
\text { instrumento, normalmente a prova, e não } \\
\text { realiza autoavaliação }\end{array}$ \\
\hline Espaço da aula & $\begin{array}{l}\text { O professor posiciona-se à } \\
\text { frente da turma, em visão de } \\
\text { destaque, com uso do quadro } \\
\text { de giz ou outro recurso, como } \\
\text { multimídia }\end{array}$ & $\begin{array}{l}\text { Permanece sentado em carteiras enfileiradas, } \\
\text { sem ter a oportunidade de dialogar, interagir } \\
\text { com colegas e com o professor }\end{array}$ \\
\hline Aula expositiva & \multicolumn{2}{|c|}{$\begin{array}{l}\text { Não é dialogada e é predominante no processo de ensino-aprendizagem em sua } \\
\text { versão mais tradicional, transmissiva, sem interação e, preferencialmente, sem } \\
\text { interrupções dos estudantes }\end{array}$} \\
\hline Atividades & \multicolumn{2}{|c|}{ Rotineiras, impostas, que privilegiam a reprodução do que foi transmitido } \\
\hline Desvantagens & \multicolumn{2}{|c|}{$\begin{array}{l}\text { Alunos dependentes do professor, sem motivação, criatividade e proatividade, } \\
\text { desestímulo ao pensamento original }\end{array}$} \\
\hline
\end{tabular}

Fonte: elaborado pelas autoras, 2017.

\section{A PRÁTICA PEDAGÓGICA UNIVERSITÁRIA POR MEIO DAS METODOLOGIAS ATIVAS: ORIENTAÇÕES METODOLÓGICAS}

Nas metodologias de ensino ativas, o processo de ensino é concebido como processo de mediação, visando à construção do conhecimento, e não à mera transmissão, como na metodologia expositiva. O professor atua como mediador: problematiza o conteúdo, faz perguntas, intervém nas atividades discentes, dialoga, aprende ao ensinar. Os alunos envolvem-se com atividades prévias às aulas, pois o planejamento e o estudo são prioridades, o que mobiliza a um engajamento dos alunos com a aula agendada, pois têm compromissos 
com a proposta didática. São organizadas atividades e trabalhos em grupos (duplas, trios, etc.), o que torna a aprendizagem mais colaborativa, além de contribuir para o exercício da tolerância.

Além disso, investe-se na autoavaliação e coavaliação dos discentes (ALTHAUS, 2016). Sendo a avaliação integrada aos processos de ensino e aprendizagem, faz-se presente a perspectiva formativa, apostando-se no desenvolvimento da autonomia dos acadêmicos, considerando que os estudantes adultos têm características próprias. E, ainda, diversificam-se os agrupamentos em sala e planejam-se atividades com os alunos. Não é preciso que todos façam as mesmas atividades o tempo todo (personalização/diferenciação do ensino) e adotase o ensino híbrido. Os espaços-tempos são diversificados, não há centralidade do quadro na sala de aula, tampouco o docente é o centro do processo (como na metodologia transmissiva), mas a comunicação, nas metodologias ativas, é horizontal entre todos os sujeitos da prática pedagógica.

Para Anastasiou e Alves (2006), a opção pelo uso da metodologia ativa pressupõe que o método de aquisição dos saberes curriculares se fará pela ação do estudante sobre o objeto de aprendizagem, possibilitando-Ihe enfrentá-lo, inicialmente no nível de compreensão em que este aprendiz se encontra, sempre mediado pela ação docente. E que essa ação seja cercada do processo reflexivo. Segundo as autoras, um pressuposto na metodologia ativa é que o conhecimento supera a simples informação, possibilitando que seu processamento seja significativo e inteligente.

Para tanto, o uso de estratégias diversas é essencial, pois estas possibilitam a exercitação de várias operações de pensamento, desde as menos complexas até as mais complexas, como o trabalho com teorias e dados na solução de problemas. É importante destacar que as estratégias não são recursos mágicos, mas ferramentas de trabalho docente e discente para consecução de objetivos propostos na proposta curricular, através da articulação entre as áreas de conhecimento que compõem o curso, processo no qual a relação teoria-prática se torna chave (ANASTASIOU; ALVES, 2006).

As metodologias ativas podem ser desenvolvidas por meio de múltiplas opções (estratégias), tais como: debates, aulas expositivas dialogadas, painel integrado, aprendizagem entre pares, sala de aula invertida, seminários, júri simulado, estudos de caso, grupo de verbalização e de 
observação (GVGO), aprendizagem baseada em problemas (PBL), projetos ou casos (GIL, 2015; ANASTASIOU; ALVES, 2006).

Segundo Roldão (2003, p. 46),

ao inscrever-se no discurso e na cultura profissional o conceito de metodologias ativas, iluminou-se o papel do aprendente, mas não se acentuou de modo correspondente a responsabilidade do ato e do modo "ativo" de ensinar [...] no processo e no sucesso da aprendizagem [...].

Ou seja, não somente os discentes devem tornar-se sujeitos ativos, mas o docente deve priorizar uma atitude ativa de mediação e orientação do processo de ensino-aprendizagem, com um planejamento didático das práticas que serão desenvolvidas no decorrer das aulas.

Nas metodologias ativas, a interação entre os professores e alunos é baseada no diálogo e na cooperação mútua, como forma de aprender, pouco a pouco, a se tornarem sujeitos críticos, pensantes, participativos, propositivos, o que, segundo Imbernón (2012), são qualidades essenciais para a constituição de um sujeito democrático.

Como síntese à perspectiva ativa, apresentamos o Quadro 2, a seguir:

Quadro 2 - Perspectivas das metodologias de ensino ativas na prática pedagógica universitária

\begin{tabular}{|c|c|c|}
\hline Sujeito & Professor & Aluno \\
\hline Participação & Mediadora e orientadora & $\begin{array}{l}\text { O aluno é ativo e engajado na propo- } \\
\text { sição da aula, a partir de seu plano } \\
\text { de trabalho ou roteiro de estudos, } \\
\text { em função dos objetivos }\end{array}$ \\
\hline Aulas & $\begin{array}{l}\text { Planeja as aulas e orienta o processo di- } \\
\text { dático juntamente com a problematiza- } \\
\text { ção dos conteúdos }\end{array}$ & $\begin{array}{l}\text { Envolve-se em atividades prévias, } \\
\text { durante e após o tempo de aula }\end{array}$ \\
\hline Conhecimento & \multicolumn{2}{|c|}{ É construído a partir de mobilização, experiências e reflexão conjunta } \\
\hline $\begin{array}{l}\text { Processo de Ensino } \\
\text { e Aprendizagem }\end{array}$ & \multicolumn{2}{|c|}{$\begin{array}{l}\text { Constroem juntos o processo de ensino e aprendizagem, o professor ensina e } \\
\text { aprende com o aluno e vice-versa }\end{array}$} \\
\hline Avaliação & $\begin{array}{l}\text { Formativa, com proposição de autoava- } \\
\text { liação e coavaliação }\end{array}$ & $\begin{array}{l}\text { O aluno participa ativamente do pro- } \\
\text { cesso de avaliação, pois a perspecti- } \\
\text { va de avaliação é formativa }\end{array}$ \\
\hline
\end{tabular}

(continua) 


\begin{tabular}{|c|c|}
\hline Espaço da aula & $\begin{array}{l}\text { Propõe o uso de recursos em maior nú- } \\
\text { mero (com ênfase na criatividade, ana- } \\
\text { logias e descoberta), e diferentes orga- } \\
\text { nizações do espaço, a fim de diferenciar } \\
\text { o ensino }\end{array}$ \\
\hline Aula expositiva & $\begin{array}{l}\text { É dialogada e ocupa um curto espaço de tempo no processo de ensino-apren- } \\
\text { dizagem }\end{array}$ \\
\hline Atividades & $\begin{array}{l}\text { São realizadas a partir de diferentes estratégias didáticas, a partir da articulação } \\
\text { entre diferentes áreas, perspectivas, experiências e reflexões }\end{array}$ \\
\hline Vantagens & $\begin{array}{l}\text { Mobiliza a autonomia dos estudantes, a originalidade, a criatividade, e desperta } \\
\text { a curiosidade e a pesquisa; estímulo à tomada de decisão, criticidade }\end{array}$ \\
\hline
\end{tabular}

Fonte: elaborado pelas autoras, 2017.

Segundo Farias, Martin e Cristo (2015), as metodologias de ensino ativas possuem algumas características, como: têm como propósito a aprendizagem significativa, favorecem o trabalho em grupo e a interdisciplinaridade, permitem a contextualização/aplicação do conhecimento na realidade do discente, fortalecem a reflexão e a atitude crítica e investigativa, além de motivar e desafiar o estudante na busca por "soluções" ou novas perspectivas para o conhecimento/conteúdo em questão.

No que respeita à diversificação do trabalho na aula universitária, talvez o desafio seria pensar na perspectiva da diferenciação do ensino, tal como já se desenvolve em muitas escolas, na proposição do trabalho diversificado com os alunos. O que poderíamos aprender a partir da experiência dos professores que ensinam crianças e jovens nas escolas? Vejamos. Se diferenciar o ensino significa "alterar o ritmo, o nível ou o gênero da instrução que o professor pratica" (HEACOX, 2006, p. 10), isto implica em responder especificamente ao progresso dos alunos, rompendo com a clássica simultaneidade do ensino: ou seja, todos fazendo a mesma coisa ao mesmo tempo, como nos primórdios da escola tradicional.

As salas de aulas diferenciadas, segundo Heacox (2006), refletem o diagnóstico do professor diante das necessidades de aprendizagem dos alunos. Pensar no ensino, segundo a autora, requer a compreensão de que um mesmo tamanho não serve para todos. E não serve, justamente, pela heterogeneidade presente na sala de aula, sob a perspectiva das necessidades comuns e também das necessidades particulares. 
De acordo com as dificuldades e potencialidades de cada grupo de estudantes, pode ser definido o ponto de partida para o estabelecimento das atividades diferenciadas (MAINARDES, 2008). Segundo o autor, existem diversas possibilidades de organização de atividades diferenciadas: "A escolha do tipo de diferenciação a ser empregada depende da habilidade do professor para avaliar a classe (de modo diagnóstico), de planejar situações de ensino diferenciadas e de manejar tarefas diferenciadas dentro de uma mesma classe" (MAINARDES, 2008, p. 131).

Outro aspecto a considerar no tocante às metodologias ativas diz respeito ao fato de que o trabalho diferenciado não deve promover o isolamento ou distinção de grupos (mais fortes/ fracos, adiantados/atrasados) na classe, mas visar a contribuir, segundo Mainardes (2008, p. 132), com a "[...] criação de classes mais igualitárias onde todos os alunos tenham a oportunidade de aprender [...]. A diferenciação das tarefas [pressupõe que] [...] a mediação do professor e a interação com colegas mais capazes são essenciais para que a aprendizagem aconteça".

Para Saint-Onge (2007, p. 134),

[...] a aprendizagem é uma atividade complexa que não procede de forma linear; há três fases essenciais a respeitar: ativar o pensamento, proceder ao tratamento das informações novas e assegurar a sincronização dos conhecimentos. Cada uma dessas fases necessita de uma interação com o aluno.

Por isso, independentemente da área, conteúdo, formação ou tendência do professor, é importante assegurar a contextualização do conhecimento à realidade do estudante universitário, além de proporcionar diferentes interações, aplicações, experiências e, ainda, a ressignificação nos casos de conteúdos que vão se ampliando ao longo do processo de ensinoaprendizagem. Saint-Onge (2007) destaca também que a aprendizagem possui quatro ideias fundamentais: é uma atividade (deve ser ativa e contextualizada para ser de qualidade); é um processo de construção (e por isso vai ampliando sua complexidade); é cumulativa (pode consolidar/ressignificar outras aprendizagens), e persegue um objetivo.

Na seção seguinte, apresentaremos algumas possibilidades para a proposição de uma aula universitária com o suporte didático das metodologias ativas. 


\section{PENSAR OS MOMENTOS DA AULA UNIVERSITÁRIA EM QUE PROFESSORES E ALUNOS DANÇAM JUNTOS}

Para Masetto (2003), a aula deve ser compreendida como um espaço de (con)vivência, ou seja, um momento para aprender com o professor e com os colegas e consolidar uma integração contextualizada à realidade, isto é, um ambiente de aprendizagem colaborativa e de construção do conhecimento. Segundo Libâneo (2013, p. 196),

[...] a aula é a forma didática básica de organização do processo de ensino. Cada aula é uma situação didática específica, na qual objetivos e conteúdos se combinam com métodos e formas didáticas, visando fundamentalmente propiciar a assimilação ativa de conhecimentos e habilidades pelos alunos. Na aula se realiza, assim, a unidade entre ensino e estudo, como que convergindo nela os elementos constitutivos do processo didático.

Uma aula pode ser subdividida em três momentos: introdução, desenvolvimento e conclusão, ou iniciação, aprofundamento e síntese integradora (GIL, 2015; FARIAS et al., 2009). Na introdução de uma aula, o professor tem como propósito mobilizar os alunos para o trabalho com o conhecimento, os quais precisam ser desafiados, sensibilizados (GASPARIN, 2002). O professor os ouve, para então "mapear" a bagagem que possuem sobre o tema proposto, e contextualiza o trabalho, apresenta os objetivos, comunica-os sobre o que se espera deles (levantamento da prática social inicial). Elencamos, a seguir, alguns encaminhamentos para iniciar uma aula, oportunizando o desenvolvimento da aprendizagem ativa dos estudantes universitários:

a. O professor apresentará algumas imagens que tenham relação com o tema da aula, por meio de um diálogo interativo (perguntas planejadas antecipadamente, visando o levantamento dos conhecimentos prévios dos alunos). Em seguida, será feita a apresentação da proposta de trabalho (planejamento do dia) no quadro ou multimídia (ou poderá ser entregue impresso), com os objetivos de aprendizagem e os momentos previstos para a aula.

b. Brainstorming (Tempestade Cerebral) para construção do conceito inicial do conteúdo da aula. Os alunos terão um tempo para que possam pensar nas questões propostas (que serão entregues digitadas em papéis), e em seguida irão ao quadro, a fim de fazer o registro de suas concepções iniciais (levantamento da Prática Social Inicial). Ao utilizar o brainstorming, o professor encoraja e alimenta o pensamento criativo na sala de aula (HEACOX, 2006, p. 152). 
c. Breve leitura de uma citação de um autor (em duplas sorteadas) para posterior verbalização à turma, visando à problematização do conteúdo a ser trabalhado.

d. O professor iniciará a aula com a leitura de um pequeno trecho de uma notícia sobre o conteúdo, para motivar os alunos à participação, a partir de três perguntas: o que vamos aprender na aula de hoje? (conteúdo); como vamos aprender? (metodologia); para que vamos aprender? (objetivo que precisam percorrer).

e. A aula iniciará com o "aluno memória" (responsável por verbalizar como foi o desenvolvimento da aula anterior). Em seguida, será feita a retomada dos conteúdos da aula anterior, por meio de perguntas planejadas previamente, com participação dos alunos para resgate dos principais aspectos discutidos. As perguntas serão sorteadas de modo criativo entre os alunos.

Com relação ao desenvolvimento da aula, é o momento de o professor problematizar e também instrumentalizar os alunos no que respeita aos conteúdos em estudo. Seguem algumas possibilidades para desenvolver o conteúdo de uma aula na perspectiva ativa:

a. A aula será desenvolvida privilegiando-se o esquema do conteúdo (temas principais), com o auxílio de materiais (exemplo: cartazes) construídos colaborativamente, por meio de exposição oral dialogada (exemplo: para a construção dos cartazes, os alunos ficarão em grupos de trabalho, com funções definidas para a atividade proposta). Tal atividade deverá ser orientada previamente, pois requer pesquisa prévia dos alunos sobre os conteúdos.

b. Por meio de perguntas planejadas, os alunos, em duplas, discutirão as questões a eles entregues sobre o conteúdo trabalhado, com apoio do artigo de autoria de um determinado autor. A partir dessa atividade, o conteúdo será desenvolvido por meio de exposição oral dialogada, com auxílio do quadro de escrever e de imagens sobre o tema.

c. Planejamento e desenvolvimento do Júri Simulado. A turma será dividida em pequenos grupos (com atribuições de papéis diferentes, durante um tempo determinado) e, a partir do estudo da dinâmica, refletirão sobre o caso estudado. Após o desenvolvimento do júri, abrir-se-á espaço para a plenária final, com a moderação e intervenção do professor.

d. Os alunos irão acessar o grupo fechado da disciplina em uma rede social para visualização das notícias postadas, visando à compreensão do conteúdo, em 
contraposição ao artigo trabalhado na aula anterior. A partir das notícias publicadas (com os registros dos alunos em ficha própria), a aula prosseguirá com exposição dialogada, por meio do quadro de escrever e faixas num painel.

Finalmente, a síntese integradora da aula é o momento para os alunos expressarem suas aprendizagens. Algumas possibilidades para finalizar a aula:

a. Retomada dos principais aspectos trabalhados na aula, por meio de perguntas reflexivas. Em atividades, os alunos responderão por escrito algumas questões sobre o tema desenvolvido. As respostas serão socializadas na próxima aula. Indicação de leituras complementares.

b. Resgate dos principais momentos vivenciados na aula, retomando os objetivos de aprendizagem propostos inicialmente. Os alunos responderão aos seguintes questionamentos (momento de autoavaliação): o que aprendi na aula de hoje? Atingi o objetivo proposto? Qual é meu compromisso com a próxima aula?

c. Para que os alunos expressem suas aprendizagens (catarse) e também se posicionem em relação aos conteúdos apreendidos (prática social final), cada grupo apresentará suas conclusões sobre a aula, com registro em um material didático (exemplo: cartolina), distribuído em pequenos grupos de alunos, enfatizando os principais aspectos do conteúdo trabalhado. Intervenções finais do professor.

\section{CONSIDERAÇÕES FINAIS}

Desenvolver práticas pedagógicas inovadoras requer, necessariamente, um processo individual de mudança do professor, o que só acontecerá se o trabalho docente for valorizado (NÓVOA; AMANTE, 2015, p. 26).

Segundo Saint-Onge (2007, p. 181), “aprender é sempre superar uma dificuldade: chegar a pensar diferente, conseguir proceder de outro modo, obter melhores desempenhos. Ensinar é sempre fornecer os conhecimentos que servem para transpor essa dificuldade." Voltando à analogia inicialmente apresentada pela via do tango: sejamos "bons condutores" (professores) da dança, auxiliemos àqueles que aprendem a dançar novas músicas, com novos ritmos, tendo como norte os objetivos para suas aprendizagens. Talvez assim os estudantes universitários possam constituir-se como futuros profissionais, ao terem compreendido o "contexto da dança" e conhecerem os saberes teóricos, mas com perspectivas críticas, inovadoras e criativas, "para dançar conforme a música". Sem isso, poderiam ser tão somente profissionais 
conhecedores da teoria, ou seja, sem terem praticado a dança, não demonstrando saber articular aquilo que aprenderam um dia juntamente com aquele que os conduziu.

A partir disso, podemos inferir, de modo provisório, que as metodologias ativas não são as únicas ferramentas para a prática pedagógica na docência universitária, mas podem contribuir para a formação de futuros profissionais que serão sujeitos reflexivos, críticos e criativos.

Por fim, segundo Raths et al. (1977, p. 374), "é fácil pensar pelos alunos. É muito mais difícil dar-lhes oportunidades para que pensem sozinhos. No entanto, se a acentuação do pensamento é um dos nossos objetivos, nós, como professores, devemos nos dedicar à criação de oportunidades para que os alunos pensem."

Tomando como referência a reflexão que aqui se desenvolveu, poderíamos afirmar que aproximar o processo de ensinar do processo de aprender, como se anunciou no título, requer, de certo modo, que possamos ser, como docentes, aprendizes permanentes da nossa profissão.

\section{REFERÊNCIAS}

ALTHAUS, Maiza Taques Margraf. Metodologias de Ensino na prática pedagógica universitária: reflexões iniciais. Palestra ministrada na Universidade Católica Dom Bosco, Campo Grande, 18 jul. 2016.

ANASTASIOU, Lea das Graças Camargo. Metodologia ativa, avaliação, metacognição e ignorância perigosa: elementos para reflexão na docência universitária. Revista Espaço para a saúde, Londrina, v. 15, n. 1, p. 19-34, jun. 2014.

ANASTASIOU, Lea das Graças Camargo; ALVES, Leonir Pessate. Processos de ensinagem na Universidade: pressupostos para as estratégias de trabalho em aula. 6. ed. Joinville: Univille, 2006.

CUNHA, Maria Isabel; SOARES, Sandra Regina. Formação do professor: a docência universitária em busca de legitimidade. Salvador: EDUFBA, 2010.

FARIAS, Isabel Maria Sabino et al. Didática e docência: aprendendo a profissão. Brasília: LiberLivro, 2009. 
FARIAS, Pablo Antonio Maia; MARTIN, Ana Luiza de Aguiar Rocha; CRISTO, Cinthia Sampaio. Aprendizagem ativa na Educação em Saúde: percurso histórico e aplicações. Rev. Bras. Educ. Med., Rio de Janeiro, v. 39, n. 1, p. 143-158, 2015.

FRANCO, Maria Amélia do Rosário Santoro. Pedagogia e prática docente. São Paulo: Cortez, 2012.

GASPARIN, João Luiz. Uma Didática para a Pedagogia Histórico-Crítica. 3. ed. Campinas: Autores Associados, 2002.

GAUTHIER, Clermont et al. Por uma teoria da pedagogia: pesquisas contemporâneas. Tradução de Francisco Pereira. ljuí: Unijuí, 1998.

GIL, Antonio Carlos. Didática do ensino superior. São Paulo: Atlas, 2015.

HEACOX, Diane. Diferenciação curricular na sala de aula. Porto: Porto Editora, 2006.

IMBERNÓN, Francisco. Inovar o ensino e a aprendizagem na universidade. São Paulo: Cortez, 2012.

LIBÂNEO, José Carlos. Didática. 2. ed. São Paulo: Cortez, 2013.

MAINARDES, Jefferson. Escola em ciclos, processos de aprendizagem e intervenções pedagógicas: algumas reflexões. In: FETZNER, Andrea Rosana (Org.). Ciclos em revista. v. 3. Rio de Janeiro: WAK, 2008. p. 118-139.

MASETTO, Marcos Tarciso. Competência pedagógica do professor universitário. São Paulo: Summus, 2003.

MORAN, José. Qual é o futuro da escola? Ou qual é a escola do futuro? 2015. Disponível em: <https://goo.gl/ZUMHux>. Acesso em: 24 maio. 2017.

NADAL, Beatriz Gomes; PAPI, Silmara de Oliveira Gomes. O trabalho de ensinar: desafios contemporâneos. In: NADAL, Beatriz Gomes (Org.). Práticas pedagógicas nos anos iniciais: concepções e ação. Ponta Grossa: Editora UEPG, 2007. p. 15-33.

NÓVOA, António; AMANTE, Lúcia. Em busca da Liberdade: a pedagogia universitária do nosso tempo. Revista de Docência Universitária, 2015. Disponível em: <https://goo.gl/ p78uPv>. Acesso em: 24 maio. 2017.

POZO, Juan Ignácio. Aprendizes e mestres: a nova cultura da aprendizagem. Porto Alegre: Artmed, 2002. 
RATHS, Louis et al. Ensinar a pensar. São Paulo: EPU, 1977.

ROLDÃO, Maria do Céu. Diferenciação curricular revisitada: conceito, discurso e práxis. Porto: Porto Editora, 2003.

ROLDÃO, Maria do Céu. Função docente: natureza e construção do conhecimento profissional. Revista Brasileira de Educação, Rio de Janeiro, v. 12, n. 34, p. 94-103, jan./ abr. 2007.

ROSSO, Ademir José; TAGLIEBER, José Erno. Métodos Ativos e Atividades de Ensino. Perspectiva, Florianópolis, v. 17, p. 37-46, 1992.

SAINT-ONGE, Michel. O ensino na escola: o que é, como se faz. 3. ed. São Paulo: Loyola, 2007.

VEIGA, IIma Passos Alencastro. A prática pedagógica do professor de Didática. 13. ed. Campinas: Papirus, 1994.

ZABALZA, Miguel. Uma nova didática para o ensino universitário: respondendo ao desafio do espaço europeu de ensino superior. Madrid, 2006.

\section{Maiza Taques Margraf Althaus}

Pedagoga (UEPG), Mestre em Educação (UEPG) e Doutora em Educação (PUC/PR). Desde 1991 é professora na UEPG, no Departamento de Pedagogia, atuando no campo da Didática nos cursos de Licenciaturas e em disciplinas de formação pedagógica para a Docência Universitária em Programas de Pós-Graduação stricto sensu. Coordena o Programa DES - Docência no ensino superior.

professoramaiza@uol.com.br

\section{Viviane Aparecida Bagio}

Doutoranda no Programa de Pós-Graduação em Educação na Universidade Estadual de Ponta Grossa (UEPG). Mestre em Educação em Ciências e em Matemática. Bacharel e Licenciada em Matemática. Licenciada em Pedagogia. Participa do Grupo de Estudos e Pesquisas em Políticas Educacionais e Formação de Professores (GEPPE/UEPG). Professora colaboradora na UEPG, no Departamento de Pedagogia. Desenvolve pesquisas nos seguintes temas: formação de professores, metodologia de pesquisa, docência universitária, educação matemática, didática. vivibagio@gmail.com 